\title{
Reliability and validity of general health questionnaire (GHQ-12) for male tannery workers: a study carried out in Kanpur, India
}

\author{
Gyan Chandra Kashyap ${ }^{*}$ and Shri Kant Singh
}

\begin{abstract}
Background: The purpose of this study was to test the reliability, validity and factor structure of GHQ-12 questionnaire on male tannery workers of India. We have tested three different factor models of the GHQ-12.

Methods: This paper used primary data obtained from a cross-sectional household study of tannery workers from Jajmau area of the city of Kanpur in northern India, which was conducted during January-June, 2015, as part of a doctoral program. The study covered 286 tannery workers from the study area. An interview schedule containing GHQ-12 was used for tannery workers who had completed at least 1 year at their present occupation preceding the survey. To test reliability, Cronbach's alpha test was used. The convergent test was used for validity. Confirmatory factor analysis was used to compare three factor structures for the GHQ-12.
\end{abstract}

Results: A total of 286 samples were analyzed in this study. The mean age of the tannery workers in this study was 38 years $(S D=1.42)$. We found the alpha coefficient to be 0.93 for the complete sample. The value of alpha represents the acceptable internal consistency for all the groups. Each item of scale showed almost the same internal consistency of 0.93 for the male tannery workers. The correlation between factor 1 (Anxiety and Depression) and factor 2 (Social Dysfunction) was 0.92. The correlation between factor 1 (Anxiety and Depression) and factor 3 (Loss of confidence) was the highest 0.98. Comparative fit index (CFI) estimate best-fitted for model-III that gave the CFI value 0.97. The SRMR indicator gave the lowest value 0.031 for the model-III.

Conclusions: The findings suggest that the Hindi version of GHQ-12 is a reliable and valid tool for measuring psychological distress in male tannery workers of Kanpur city, India. Study found that the model proposed by the Graetz was the best fitted model for the data.

Keywords: Cronbach's alpha, Confirmatory factor analysis, GHQ-12, Internal consistency, Reliability, Tannery, Validity

\section{Background}

The General Health Questionnaire (GHQ)-12 is a wellknown and efficient tool for measuring the mental health status of the respondent subjects. The GHQ-12 scale is used worldwide in different segments of practice and research - clinical, epidemiological and psychological $[1,2]$. When it was first introduced, the General Health Questionnaire contained 60 items in the scale,

\footnotetext{
* Correspondence: statskashyap@gmail.com
Department of Mathematical Demography and Statistics, International
Institute for Population Sciences, Govandi Station Road, Deonar Mumbai

* Correspondence: statskashyap@gmail.com

* Correspondence: statskashyap@gmail.com
Department of Mathematical Demography and Statistics, International
Institute for Population Sciences, Govandi Station Road, Deonar Mumbai 400088, India 400088, India
}

which were subsequently reduced to 30 , then 28 items and, finally, to just 12 items $[3,4]$ in its present form.

GHQ-12 is the most refined scale for measuring the psychological well-being of various segments of the human population [5]. Many studies have validated GHQ12 tool as a reliable measure of mental health in different segments of populations across countries [6-20].

It is evident from the study of a systematic review across occupational and population based studies provides the comparative results for occupational and population based study for GHQ-12 scale. Results from the study indicate a higher prevalence of mental health for 
the occupational based studies in comparison of population based studies [21].

Questionnaire consists of 12 items with each item measuring the severity of mental health problems in the 4 weeks preceding the study. Each item was assessed on a four-point scale (less than usual, no more than usual, rather more than usual, much more than usual). In this study GHQ-12 used the four-point Likert scale (1 to 4). The minimum possible total score is 12 and maximum, 48. The positive items are recoded from 1 (not at all) to 4 (much more than usual) and negative items from 4 (not at all) to 1 (much more than usual). As the application of GHQ-12 in any research setting is welldocumented, it was decided to translate it into Hindi. (Hindi language).

Tanneries have attained considerable notoriety for the polluting nature of their work and the serious occupational health risks like mental health disorder, respiratory problems, musculoskeletal disorder, injuries etc. that they pose. Male tannery workers are constantly exposed to many harmful chemicals and physical hazards. Male tannery workers usually involved in many hazardous work process loading and unloading of raw hides, transferring the work, lifting the raw hides etc. in tannery premises. There is high risk of developing mental health disorder in such working conditions. The poor and unsafe working conditions act as stressors and increase the susceptibility of the male tannery workers. This study utilized the Hindi version of GHQ-12 scale to measure the mental health status of male tannery workers of Kanpur city, India. In present study we have tested GHQ-12 scale for the tannery workers, because they work in very hazardous work environment along with involvement in chromium exposure during tanning process, leather dust, exposure to chemical agents, ergonomic stressor increases their susceptibility which can be linked to mental health problem. So for, this study has tested the reliability, validity and factor structure of GHQ-12 scale for male tannery workers.

\section{Methods}

Data for the present research was drawn from a crosssectional household study of tannery workers in the Jajmau area of Kanpur City in the state of Uttar Pradesh, India. The study was conducted during the period January-June, 2015, and was part of a PhD program. All total 286 tannery workers from the study area were interviewed.

A three-stage sampling design was used. In the first stage, we selected seven areas in which most households have members working in the tanneries of nearby Jajmau. In second stage, three areas were selected on the basis probability proportion to size (PPS) i.e., the highest number of households with tannery workers in the area. In the third stage, we listed the households in which at least one member was a tannery worker. If a household was found to have more than one member working in tanneries, we selected the respondent through KISH table. In this manner, 100 samples were selected from each area through systematic random sampling. The three selected areas were Budhiyaghat, Tadbagiya and Ashrafabad in the Jajmau suburban part of Kanpur city.

GHQ-12 English version scale had been translated into Hindi version by following the standard procedure. Intensive pre-testing was done with the tannery workers of Jajmau area for testing the internal consistency the GHQ-12 tool of Hindi version. Before starting the interviews, we have explained about the purpose of the survey and requested to participate in the survey. After that face-to-face interviews were conducted among those who agreed to participate by using a structured pretested questionnaire on the tannery workers. Suitable statistical techniques were used to meet the objectives of study. The correlation matrix was constructed to understand the correlation between the items of GHQ- 12 . The item-scale analysis of GHQ-12 was also performed. Cronbach alpha test was used to estimate the reliability (internal consistency) of GHQ-12 for the male tannery workers who participated in the study.

A large number of studies has used confirmatory factor analysis for estimating the factor structure of the GHQ-12 scale. This study had verified three different models. Model 1 was unidimensional. Model II contained the two factors: the first factor had all six positively worded items, and factor two had all six negatively worded items [22]. Model III include three factors: Anxiety and depression, Social Dysfunction and Loss of confidence [23]. The present study has used the maximum likelihood method for estimating the factor loading for the three different models. To test the goodness of fit, we have assessed the following indices; RMSEA: Root mean squared error of approximation, AIC: Akaike's information criterion, BIC: Bayesian information criterion, CFI: Comparative fit index, TLI: Tucker-Lewis index, SRMR: Standardized root mean squared residual.

\section{Description of the indices RMSEA}

The RMSEA estimate the parameter of the model that fit the population's covariance matrix. Presently RMSEA was known as one of the most informative fit indices due to its sensitivity to the number of estimated parameters in the model. The cut-off value of RMSEA estimates varies from 0.6 to 0.7 within this range model is acceptable or best fit [24].

\section{AIC}

AIC considered as the first model criterion. Currently, it is most widely used model selection tool. AIC used to 
delineate between different fitted models having the same dimension [25].

\section{$B I C$}

In the computation of BIC based on the empirical loglikelihood and does not require the specification of priors. Basically, BIC has an asymptotic approximation to a transformation of the Bayesian posterior probability of a model [26].

\section{$\mathrm{CFI}$}

Comparative fit index measures the fit of the model even when the sample size is small. The values are closer to 1 indicating the suitable model. But, cut off criterion of CFI $\geq 0.90$ is acceptable. At present CFI is one of the most popularly fit indices because measures least affected by sample size [24, 27, 28].

\section{TLI}

TLI an index that prefers the simpler models. This index is well accepted where sample size is very small, and it gives the most accurate results. Due to the non-normed characteristics of this index value which can exceed above 1.0, which create some problem in the interpretation of the result. The cut-off point is 0.80 for this index while researcher suggested TLI $\geq 0.95$ the threshold level [25].

\section{SRMR}

The SRMR describe the square root of the difference between the residuals of the sample covariance matrix and the hypothesized covariance model. The value of SRMR ranges 0 to 1 for fitting the model. The value 0 indicates the perfect fit and values as high as 0.08 are acceptable [26].

\section{Participants}

The study comprised 286 male tannery workers of age group 18-70 years from Jajmau in suburban Kanpur.

\section{Results}

\section{Descriptive findings}

Table 1 presents the descriptive findings of the study. The mean age of tannery workers was $38(\mathrm{SD}=1.42)$ years. Around $66 \%$ of the tannery workers were illiterate and only $11 \%$ had studied up to high school and above. The majority (89\%) of tannery workers were on temporary job contracts, and their mean work experience in their present workplaces was $10(\mathrm{SD}=0.92)$ years. They were involved in different types of work in the tanneries they were working in: beam house work $(8.42 \%$ of the workers), wet finishing (24.21\%), dry finishing (50.53\%) and miscellaneous (16.84\%). The respondent tannery workers also reported that they worked almost every day
Table 1 Socio-economic and work-related characteristics of tannery workers in Kanpur city, India, 2015

\begin{tabular}{|c|c|c|}
\hline Variables & Tannery workers (\%) & (Numbers, N) \\
\hline Age in years ${ }^{a}$ & $38.55 \pm 1.42$ & 286 \\
\hline \multicolumn{3}{|l|}{ Education } \\
\hline Illiterate & 66.32 & 189 \\
\hline Up to primary & 13.33 & 38 \\
\hline Middle school & 8.77 & 25 \\
\hline High school \& above & 11.58 & 33 \\
\hline $\begin{array}{l}\text { Work experience in current } \\
\text { tannery }\end{array}$ & $10.10 \pm 0.92$ & 285 \\
\hline $\begin{array}{l}\text { Work experience in previous } \\
\text { tannery }{ }^{\mathrm{a}}\end{array}$ & $7.95 \pm 1.25$ & 99 \\
\hline \multicolumn{3}{|l|}{ Job status } \\
\hline Temporary job (daily wages) & 89.12 & 254 \\
\hline Permanent job & 10.88 & 31 \\
\hline \multicolumn{3}{|l|}{ Type of work } \\
\hline Beam house work & 8.42 & 24 \\
\hline Wet finishing work & 24.21 & 69 \\
\hline Dry finishing work & 50.53 & 144 \\
\hline Miscellaneous work & 16.84 & 48 \\
\hline Average working hours in day ${ }^{a}$ & $9.54 \pm 0.19$ & 285 \\
\hline Average working days in a week ${ }^{a}$ & $6.50 \pm 0.06$ & 285 \\
\hline \multicolumn{3}{|l|}{ Religion } \\
\hline Hindu & 33.92 & 97 \\
\hline Muslim & 66.08 & 189 \\
\hline \multicolumn{3}{|l|}{ Caste } \\
\hline $\mathrm{SC} / \mathrm{ST}$ & 65.38 & 187 \\
\hline Other backward classes & 18.53 & 53 \\
\hline Others & 5.59 & 16 \\
\hline Don't know & 10.49 & 30 \\
\hline \multicolumn{3}{|l|}{ Exposure to the media } \\
\hline No exposure & 23.8 & 66 \\
\hline Any exposure & 76.92 & 220 \\
\hline
\end{tabular}

in the week with 9 to10 hours as the mean working day. Mean number of working days was $6.50(\mathrm{SD}=0.06)$ and duration of a working day was 9.54 $(\mathrm{SD}=0.19)$ hours.

About two-thirds of the workers were Muslims $(66.08 \%)$ and one-third of them Hindus. The majority of the tannery workers $(65.38 \%)$ belonged to SC/ST caste groups. Significantly, $6 \%$ belonged to the Other castes.

Table 2 presents the correlation matrix of unidirectional GHQ-12 items with inter-item reliability and the value of Cronbach's $\alpha$ coefficient. The correlation matrix shows the statistical measure of association between the GHQ-12 items. Item 1 shows the high correlation with the item 3 and negative correlation with the item 6 . Further, Item 6 show the negative correlation with the item 
Table 2 Correlations between items in GHQ-12 scale, Inter-item reliability

\begin{tabular}{|c|c|c|c|c|c|c|c|c|c|c|c|c|c|}
\hline & Item 1 & Item 2 & Item 3 & Item 4 & Item 5 & Item 6 & Item 7 & Item 8 & Item 9 & Item 10 & Item 11 & Item 12 & Inter-item Reliability ${ }^{a}$ \\
\hline Item 1 & 1 & & & & & & & & & & & & \\
\hline Item 2 & 0.46 & 1.00 & & & & & & & & & & & 0.497 \\
\hline Item 3 & 0.73 & 0.50 & 1.00 & & & & & & & & & & 0.523 \\
\hline Item 4 & 0.64 & 0.51 & 0.73 & 1.00 & & & & & & & & & 0.494 \\
\hline Item 5 & 0.49 & 0.60 & 0.50 & 0.48 & 1.00 & & & & & & & & 0.506 \\
\hline Item 6 & -0.70 & -0.39 & -0.70 & -0.56 & -0.38 & 1.00 & & & & & & & 0.524 \\
\hline Item 7 & 0.69 & 0.43 & 0.61 & 0.59 & 0.40 & -0.60 & 1.00 & & & & & & 0.510 \\
\hline Item 8 & 0.51 & 0.41 & 0.50 & 0.62 & 0.37 & -0.49 & 0.56 & 1.00 & & & & & 0.503 \\
\hline Item 9 & 0.55 & 0.53 & 0.55 & 0.53 & 0.54 & -0.50 & 0.44 & 0.30 & 1.00 & & & & 0.530 \\
\hline Item 10 & 0.51 & 0.46 & 0.53 & 0.50 & 0.52 & -0.48 & 0.48 & 0.29 & 0.64 & 1.00 & & & 0.505 \\
\hline Item 11 & 0.60 & 0.61 & 0.55 & 0.53 & 0.59 & -0.47 & 0.55 & 0.39 & 0.69 & 0.66 & 1.00 & & 0.512 \\
\hline Item 12 & 0.71 & 0.48 & 0.63 & 0.56 & 0.44 & -0.62 & 0.69 & 0.41 & 0.57 & 0.43 & 0.53 & 1.00 & 0.504 \\
\hline
\end{tabular}

${ }^{a}$ Average inter-item reliability: 0.50 ; Cronbach's a coefficient: 0.93

$7,8,9,10,11,12$. Item 7 show the lowest correlation with item 9, and it was the highest with the item 12 . Item 8 had the lowest correlation with the item 10. The inter-item correlation of GHQ-12 items was ranged from 0.49 to 0.53 . And the average inter-item correlation was 0.50 . Cronbach's alpha test is one of the most commonly used tools to test reliability estimates and was employed in this study to test the internal consistency of GHQ-12 questionnaire for the male tannery workers. We found the alpha value to be 0.93 for the entire sample. The value of alpha represents the acceptable internal consistency for all the groups.

\section{Confirmatory factor analysis}

Table 3 shows goodness-of-fit statistics for the three models estimated in this study. Model 1 was unidimensional. Model II contained two factors, and Model III include three factors: Anxiety and depression, Social Dysfunction and Loss of confidence [23]. Confirmatory factor analysis gave the lowest RMSEA value in modelIII although all three models estimated the RMSEA's value more than 0.08 . Results show the lowest AIC and $\mathrm{BIC}$ value in model-II, whereas it was the highest in

Table 3 Goodness-of-fit of three confirmatory factor analysis models $(N=286)$

\begin{tabular}{llll}
\hline Statistics & Model-I & Model-II & Model-III \\
\hline RMSEA & 0.127 & 0.171 & 0.091 \\
AIC & 7552.22 & 3786.02 & 4008.18 \\
BIC & 7687.23 & 3851.70 & 4073.86 \\
CFI & 0.892 & 0.930 & 0.973 \\
TLI & 0.865 & 0.884 & 0.955 \\
SRMR & 0.061 & 0.420 & 0.031 \\
\hline
\end{tabular}

RMSEA Root mean squared error of approximation, AIC Akaike's information criterion, BIC Bayesian information criterion, CFI Comparative fit index, TL Tucker-Lewis index, SRMR Standardized root mean squared residual
model-I. Comparative fit index (CFI) estimate best-fitted model-III that gave the CFI value 0.97 along with CFI value 0.93 in model-II. In all the three models TLI estimates ranged $0.86-0.95$. The cut-off point of TLI was 0.80 , and the threshold level was 0.95 that is acceptable. The SRMR indicator gave the lowest value 0.031 for the model-III. The value close to 0 indicates the perfect fit and the value up to 0.08 are acceptable. The model-III was the best model fitted for the data that given the better estimates of four indicators than model-I and model-II.

Figure 1 shows the standardized factor loadings and between factor correlations of positive worded (PW) items and negatively worded items (NW) in model II. The factor loading ranged between - 0.66-0.86. The positive worded (PW) items had higher correlations that range from $0.62-0.86$ then negatively worded items and the correlation between negatively worded items ranged - 0.66- 0.83 . Factor 1 includes all positively worded items and factor 2 includes all negatively worded items. The correlation between factor 1 (Social Dysfunction) and factor 2 (Anxiety and Depression) was 0.85 .

Figure 2 shows the standardized factor loadings and between factor correlation of model III. The factor loading ranged between -0.69-0.98. The result shows the strong relationship between the three factors of the model III. The correlation between factor 1 (Anxiety and Depression) and factor 2 (Social Dysfunction) was 0.92. And, the correlation between factor 2 (Social Dysfunction) and factor 3 (Loss of confidence) were 0.78 . The correlation between factor 1 (Anxiety and Depression) and factor 3 (Loss of confidence) was the highest 0.98. It is evident from the strong correlations between the three factors confirm that Graetz's 3-factor model fitted the data in better than two other models in this study. 


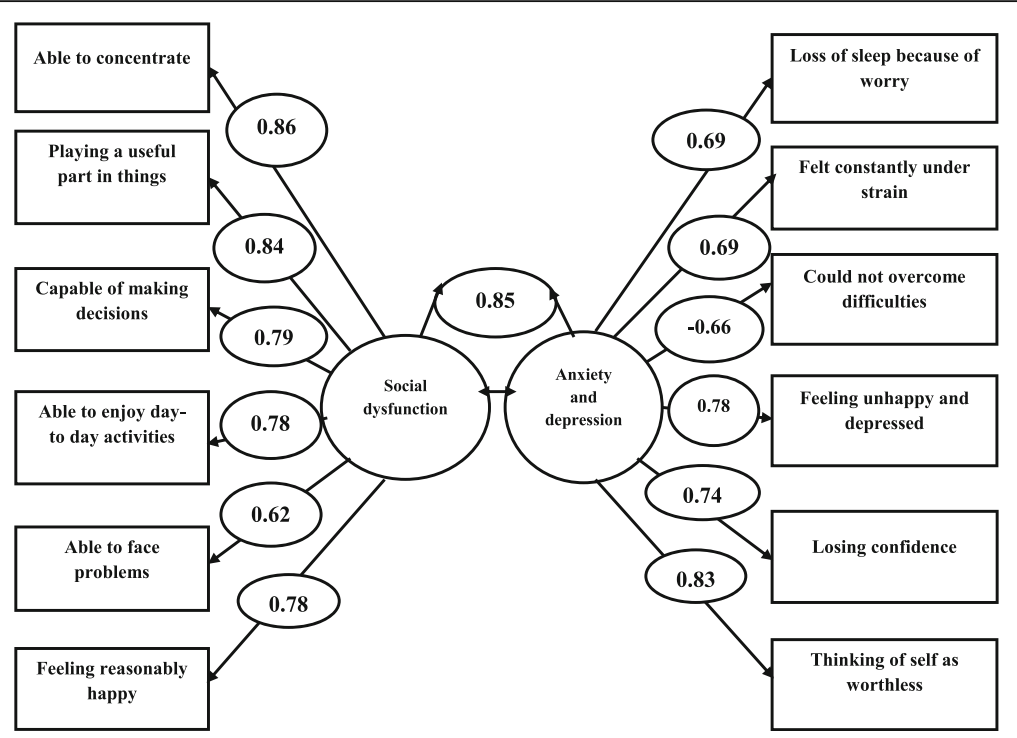

Fig. 1 Standardized factor loadings and between-factor correlations between model I and model II

\section{Discussion}

The GHQ-12 is the most refined and familiar scale for measuring the psychological well-being of diverse groups of people in different settings [6-20]. The GHQ-12 has been translated into several languages worldwide $[7,9,13,16-18,20]$. The aim of this study was to translate and test the reliability, validity and factor structure of GHQ-12 questionnaire for male tannery workers in India. The GHQ-12 scale is also acknowledged for its reliability in measuring the perceived general health status of employees working in different sectors [21, 29], which is a reason for its widespread acceptance. There are different strategies for estimating reliability. The commonly-used ones are test-retest reliability, equivalent (or parallel) forms reliability and internal consistency reliability [30,31]. This study used the internal consistency reliability method.

There are different methods for testing reliability that are based on the theory of estimation of test reliability.

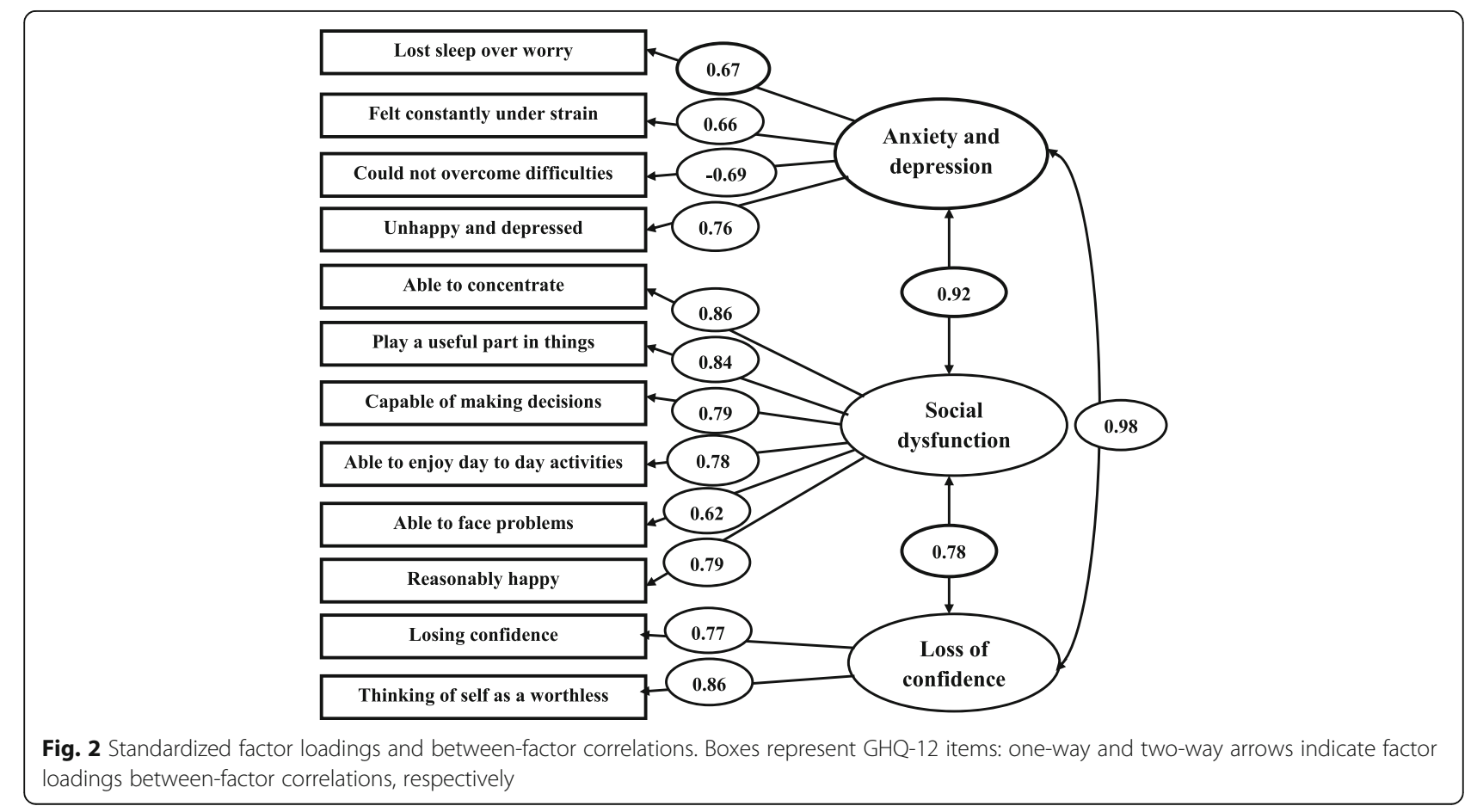


They include Spearman-Brown prophecy formula, KuderRichardson formulas (KR-20 and KR-21), and Cronbach alpha, which is also called the alpha coefficient [32]. The Cronbach alpha test is more flexible because it can be applied when test item scores are dichotomous as well as when they are scored on the Likert scale. KR-20 or KR-21 methods can be applied only when test-item scores have dichotomous values. Therefore, this study used Cronbach alpha test for testing the reliability. An alpha test coefficient of 0.93 was obtained for the entire sample, which is a universally accepted value for confirming reliability [33]. We may then conclude that, for this study, this is a highly reliable and valid scale.

Confirmatory factor analysis was used to compare three-factor structures for the GHQ-12 scale. This study has estimated the indices RMSEA, AIC, BIC, CFI, TLI, and SRMR. The study has used a unidimensional model that is model-I, model-II contain the two factors: positively worded items and negatively worded items. The third model was proposed by the Graetz: anxiety and depression, social dysfunction and loss of confidence. Our results show that the unidimensional model was the poorest fit that evidence from the estimated indices. The two-factor model estimated some of the indicators which are in the acceptable range. Few studies had mentioned the two-factor model that is an artificial grouping of all positively worded items and all negatively worded items. The two-factor model also fit the model for selected indicators in the study. The threefactor model proposed by the Graetz that was the bestfitted model. The result shows that all the factor had the strong correlation with each other. The correlation between factor 1 and factor 2 was 0.92 . And, the correlation between factor 2 and factor 3 was 0.78 . The correlation between factor 1 and factor 3 was the highest 0.98. Several previous studies also documented the strong association between the three actors and bestfitted model in the different data sets [34-39].

\section{Conclusions}

Our results showed that Hindi version of the GHQ-12 is a reliable and valid tool for measuring psychological distress among the male tannery workers. Our analysis of the three-factor model proposed by the Graetz found the best fit model; all three factors were strongly correlated with each other.

\section{Abbreviations \\ GHQ: General Health Questionnaire; PPS: Probability Proportional to Size; SC/ST: Schedule Caste/Schedule Tribes; SD: Standard Deviation}

\section{Acknowledgments}

The authors are thankful to all the participants in the survey. We are also grateful to Mr. Ashish Kumar Upadhyay and Mr. Praveen Chokhandre for their help in revising the manuscript.
Funding

We have not received any funding for this study.

Availability of data and materials

Data will not be shared in order to protect the participants identities.

\section{Authors' contributions}

GCK developed the questionnaire, collected the data, contributed in acquisition of data, statistical analysis of data and wrote the manuscript. SKS enhanced the questionnaire, contributed to the concept and design of the paper, literature searches and critically revised the manuscript. Both authors read and approved the final manuscript.

Competing interests

The authors declare that they have no competing interests.

\section{Ethics approval and consent to participate}

We have received the ethical clearance from the committee. The study was approved by the Student Research Ethics Committee of International Institute for Population Sciences Mumbai, India. We have also received a consent to participate from each of the respondent before starting the interview.

Received: 19 May 2016 Accepted: 30 December 2016

Published online: 21 March 2017

\section{References}

1. Zulkefly NS, Baharudin R. Using the 12-item general health questionnaire (GHQ-12) to assess the psychological health of Malaysian college students. Global J Health Sci. 2010;2:1

2. Killic C, Rezaki M, Rezaki B, Kaplan I, Ozgen G, Sagduyu A, Ozturk MO. General health questionnaire (GHQ-12, GHQ-28): psychometric properties and factor structure of the scales in a Turkish primary care sample. Soc Psychiatry Psychiatr Epidemiol. 1997:32:327-31.

3. Goldberg D, Williams P. A User's guide to the general health questionnaire Windsor. Berks, NFER-Nelson; 1988

4. Goldberg DP, Hillier VF. A scaled version of the general health questionnaire. Psychol Med. 1979:9:139-45.

5. McDowell I. Measuring health: a guide to rating scales and questionnaire. USA: Oxford University Press; 2006

6. Quek KF, Low WY, Razack AH, Loh CS. Reliability and validity of the general health questionnaire (GHQ-12) among urological patients: a Malaysian study. Psychiatry Clin Neurosci. 2001;55:509-13.

7. Muhamad SBY. The sensitivity, specificity and reliability of the Malay version 30-item general health questionnaire (GHQ-30) in detecting distressed medical students. Education in Medicine Journal. 2010;2(1):e12-21. doi:10.5959/eimj.2.1.2010

8. Toyabe S, Shioiri T, Kobayashi K, Kuwabara H, Koizumi M, Endo T, Ito M, Honma H, Fukushima N, Someya T, Akazawa K. Factor structure of the general health questionnaire (GHQ-12) in subjects who had suffered from the 2004 Niigata-Chuetsu earthquake in Japan: a community-based study. BMC Public Health. 2007;7:175. doi:10.1186/1471-2458-7-175.

9. Montazeri A, Harirchi AM, Shariati M, Garmaroudi G, Ebadi M, Fateh A. The 12-item general health questionnaire (GHQ-12): translation and validation study of the Iranian version. Health Qual Life Outcomes. 2003;1:66.

10. Doi Y, Minowa M. Factor structure of the 12-item general health questionnaire in the Japanese general adult population. Psychiatry Clin Neurosci. 2003:57:379-83.

11. Abeysena C, Jayawardana P, Peiris U. Factor structure and reliability of the 12-item Sinhala version of general health questionnaire. International Journal of Collaborative Research on Internal Medicine \& Public Health. 2012:4:8.

12. Ibrahim N, Osman ZJ, Jan KONN, Ismail SIF, Kar PC, Mukhtar F, Sidik SM. Reliability and factor structure of the general health questionnaire-12 among university students. Malaysian Journal of Medicine and Health Sciences, 2014; (ISSN 1675-8544); 10 (2): 53-60.

13. Smith AB, Fallowfield $\amalg$, Stark DP, Velikova G, Jenkins V. A Rasch and confirmatory factor analysis of the general health questionnaire (GHQ)-12. Health Qual Life Outcomes. 2010;8:45.

14. Kuruvilla A, Pothen M, Philip K, Braganza D, Joseph A, Jacob KS. The validation of the Tamil version of the 12 item general health questionnaire. Indian J Psychiatry. 1999;41(3):217. 
15. Chan DW. The Chinese general health questionnaire in a psychiatric setting The development of the Chinese scaled version. Soc Psychiatry Psychiatr Epidemiol. 1993;28:124-9.

16. Najarkolaei FR, Raiisi F, Rahnama P, Fesharaki MG, Zamani O, Jafari MR, Montazeri A. Factor structure of the Iranian version of 12-item general health questionnaire. Iran Red Crescent Med J. 2014;16(9):e11794. doi:10.5812/ircmj.11794.

17. Kim YJ, Cho MJ, Park S, Hong JP, Sohn JH, Bae JN, Jeon HJ, Chang SM, Lee HW, Park J. The 12-item general health questionnaire as an effective mental health screening tool for general Korean adult population. Korean Psychiatry Investig. 2013;10(4):352-8. https://synapse.koreamed.org/DOlx. php?id=10.4306/pi.2013.10.4.352.

18. Jacob KS, Bhugra D, Mann AH. The validation of the 12-item general health questionnaire among ethnic Indian women living in the United Kingdom. Psychol Med. 1997:27:1215-7. Cambridge University Press

19. Politi PL, Piccinelli M, Wilkinson G. Reliability, validity and factor structure of the 12-item general health questionnaire among young males in Italy. Acta Psychiatr Scand. 1994;90:432-7.

20. Daradkeh TK, Ghubash R, El-rufaie OE. Reliability, validity, and factor structure of the Arabic version of the 12-item general health questionnaire. Psychol Rep. 2001;89:85-94

21. Goodwin L, Ben-Zion I, Fear NT, Hotopf M, Stansfeld SA, Wessely S. Are reports of psychological stress higher in occupational studies? A systematic review across occupational and population based studies. PLoS One. 2013:8(11):e78693.

22. Andrich D, Schoubroeck LV. The general health questionnaire: a psychometric analysis using latent trait theory. Psychol Med. 1989;19:469-85.

23. Graetz B. Multidimensional properties of the general health questionnaire. Soc Psychiatry Psychiatr Epidemiol. 1991;26:132-8.

24. Hooper D, Coughlan J, Mullen M. Structural equation modelling: guidelines for determining model fit. Articles. 2008:2.

25. Cavanaugh JE. 171: 290 model selection lecture II: the Akaike information criterion; 2012.

26. Cavanaugh JE, Neath AA. Generalizing the derivation of the Schwarz information criterion. Communications in Statistics-Theory and Methods 28. 1999;1:49-66.

27. Finney SJ, DiStefano C. Non-normal and categorical data in structural equation modeling. Structural equation modeling: A second course. 2006;269-314

28. Li-tze H, Bentler PM. Cutoff criteria for fit indexes in covariance structure analysis: conventional criteria versus new alternatives. Struct Equ Model Multidiscip J. 1999:6(1):1-55.

29. Karatza C, Zyga S, Tziaferi S, Prezerakos P. Workplace bullying and general health status among the nursing staff of Greek public hospitals. Ann General Psychiatry. 2016;15:7. doi:10.1186/s12991-016-0097-z.

30. Brown JD. The Cronbach alpha reliability estimate. Shiken: JALT Testing \& Evaluation SIG Newsletter. 2002;6(1):17-9.

31. Brown JD. Testing in language programs. Upper Saddle River: Prentice Hall; 1996.

32. Kuder GF, Richardson MW. The theory of estimation of test reliability. Psychometrika. 1937;2:151-60.

33. Cronbach L. Essentials of psychological testing. 3rd ed. New York: Harper \& Row; 1970.

34. Gao F, Luo N, Thumboo J, Fones C, Shu-Chuen L, Yin-Bun C. Does the 12item general health questionnaire contain multiple factors and do we need them. Health Qual Life Outcomes. 2004;2(1):1.

35. Molina JG, Rodrigo MF, Josep-Maria L, Vives J. Wording effects and the factor structure of the 12-item general health questionnaire (GHQ-12). Psychol Assess. 2014;26(3):1031.

36. Aguado J. Campbell a, Ascaso C, Navarro P, Garcia-Esteve L, Juan VL. Examining the factor structure and discriminant validity of the 12-item general health questionnaire (GHQ-12) among Spanish postpartum women. Assessment. 2010; 1073191110388146.

37. Cheung YB. A confirmatory factor analysis of the 12-item general health questionnaire among older people. Int J Geriatr Psychiatry. 2002;17:739-44

38. Kalliath TJ, O'Driscoll MP, Brough P. A confirmatory factor analysis of the general health questionnaire-12. Stress Health. 2004;20:11-20.

39. French DJ, Tait RJ. Measurement invariance in the general health questionnaire-12 in young Australian adolescents. Eur Child Adolesc Psychiatry. 2004;13:1-7.

\section{Submit your next manuscript to BioMed Central and we will help you at every step:}

- We accept pre-submission inquiries

- Our selector tool helps you to find the most relevant journal

- We provide round the clock customer support

- Convenient online submission

- Thorough peer review

- Inclusion in PubMed and all major indexing services

- Maximum visibility for your research

Submit your manuscript at www.biomedcentral.com/submit
C Biomed Central 